\title{
Evolution Analysis of Synthetic Biotechnology from the Perspective of Multiple Knowledge Network
}

\author{
Rongfang Liu \\ School of Business Administration, South China University of Technology, Guangzhou, China \\ Email: liurongfang0829@163.com
}

How to cite this paper: Liu, R.F. (2019) Evolution Analysis of Synthetic Biotechnology from the Perspective of Multiple Knowledge Network. American Journal of Industrial and Business Management, 9, 366-384.

https://doi.org/10.4236/ajibm.2019.92025

Received: February 2, 2019

Accepted: February 25, 2019

Published: February 28, 2019

Copyright $\odot 2019$ by author(s) and Scientific Research Publishing Inc. This work is licensed under the Creative Commons Attribution-NonCommercial International License (CC BY-NC 4.0). http://creativecommons.org/licenses/by-nc/4.0/

\begin{abstract}
Science and technology that function as knowledge resources have shown a complex relation in the process of innovation, especially in the synthetic biotechnology industry, an industry bridging biology and engineering where its standardized, decoupled and modularized innovation mode has reconstructed rather than simply spanned the institutions of academic and industrial worlds. Multiple knowledge networks open a new avenue for studying the evolution of synthetic biotechnology. This paper first proposes a framework of integrating scientific and technological knowledge networks, then utilizes WOS's Cross Search function to construct the cross-reference between DII and SCI and SSCI, finally employs the indicators of network structures and nodes to analyze the multiple knowledge networks in the evolution of synthetic biotechnology. Results show that at the emergence stage (2000-2003), scientific and technological knowledge are difficult to integrate with each other; at the exploration stage (2004-2007), there exist significant intersection and symbiosis between scientific and technological knowledge; and at the growth stage (2008-2014), scientific and technological knowledge give rise to independent logics of growth.
\end{abstract}

\section{Keywords}

Synthetic Biotechnology, Scientific Knowledge Network, Technological Knowledge Network, Technological Evolution

\section{Introduction}

Synthetic biotechnology originated from the launch of the human genome project and the rise of system biology in the 1990s. Life scientists use the concept 
of electronic circuits in physics for reference to construct gene circuits with specific functions and logical relationships, and endow cells with new biological functions at the functional level [1]. With the great potential to promote the transformation of the biotechnology industry and solve the global food and energy crisis, the UK and the United States have successively promoted its monopoly in the global synthetic biotechnology innovation value chain through the establishment of synthetic biology research centers, the establishment of synthetic biology research networks, and the formulation of national synthetic biology development plans [2] [3]. China's synthetic biotechnology started relatively late. Since 2011, the Ministry of Science and Technology has successively approved 10 related 973 projects and 1 related 863 projects. The scope of funding mainly covers industrial synthetic biotechnology, and the targets of funding are mainly microbial systems that are easier to design. It is urgent to study the evolutionary model of synthetic biotechnology, especially the innovative features at now stage, to provide a theoretical basis for China to catch up with developed countries in synthetic biotechnology and other emerging industries.

Synthetic biotechnology bridges two major disciplines, life sciences and engineering. The subversive innovations it has achieved over the past decade have been driven by a number of scientific achievements and technological advances [4]. However, scientific knowledge and techno-logical knowledge in the evolution of synthetic biotechnology present a seemingly contradictory combination. On the one hand, technological innovation requires deep integration of disciplines such as life sciences, engineering, mathematics, chemistry, and physics. On the other hand, the construction of innovative value chains presents standardized, decoupled and modularized innovation mode [5]. Building complex networks is a hot topic in the research of technological innovation in recent years [6], among which knowledge networks have received more and more attention [7] [8]. Because there is no direct correspondence between organizations/researchers and knowledge elements, as the original driving force of innovation, science and technology present a mixed state in the process of technological evolution [9]. It is difficult to clarify the complex knowledge flow in a single-layer knowledge network in the general sense. Although scholars in the field of innovation have done a lot of research on biotechnology, the understanding of synthetic biotechnology has always remained at the general branch of biotechnology. It is urgent to further study the influence of scientific knowledge and technological knowledge on the evolution of synthetic biotechnology, so as to provide theoretical basis for formulating scientific and techno-logical policies and planning industrial layout. Therefore, this paper proposes an analysis framework integrating scientific knowledge network and technological knowledge network to deconstruct the heterogeneous role of science and technology in the evolution of synthetic biotechnology.

Multiple networks are dynamic, reflecting the variability of individual networks and the linkage between networks. Over time, the network may be deformed, nested or separated. In some cases, it shows a trend of decline or even 
disintegration. The existing research mainly focuses on the discussion and analysis of the network evolution model and its motivation [10]. Cannella and McFadyen's research found that the knowledge creation in the previous stage will have an impact on the strength of the connections between knowledge nodes in the latter stage of the network [11]. Demirkan and Deeds identified the main factors driving the evolution of scientific networks based on the data of 367 US biotech enterprises from 1990 to 2006, including network size, network strength and knowledge quality [12]. These researchers have found the variability of individual networks, but little consideration has been given to the linkage between networks at different levels. Because of the correlation between scientific knowledge network and technological knowledge network in the innovation path and the innovation resources, this paper uses network structure and node index to further open the "black box" of synthetic biotechnology evolution.

\section{Research Design}

\subsection{Conceptual Model}

Building a multiple network is a frontier trend in complex network research, such as building a multiple network of social networks and their sub-networks [13] [14], as well as the construction of a multiple network of social networks and knowledge networks [7] [8] [15] [16]. However, existing re-searches usually treat different types of knowledge as homogeneous knowledge [17] [18], neglecting the difference between the two types of heterogeneous knowledge driven by science and technology. Therefore, this paper proposes an analytical framework that integrates scientific knowledge net-works and technological knowledge networks, and takes synthetic biotechnology as an example for empirical research.

Patent citation information system is an effective way to study knowledge flow problems at present, which can link industrial development with related scientific and technological fields [19]. References are often cited in the process of patent application and examination by examiners, which can be divided into two categories: one is other patents, and the other is non-patent literature, namely scientific literature. Although literature and patents as innovation achievements cannot clearly point to science-based innovation or technology-based innovation, the original driving force for innovation is the coding of scientific knowledge and technological knowledge. Most of the existing researches use the backward citation quantity or proportion of focal patents to non-patent literature and other patents to compare and analyze the dependence of the industry on scientific knowledge and technological knowledge [20]. However, the patent application process always contains some wrong or invalid citation sources, and the process is affected by the technology life cycle. It is limited to study knowledge flow only by the number of citations. In recent years, some scholars have proposed optimization models or algorithms to improve the scientificalness of patent analysis, such as a structural method integrating patent citation information 
and text mining technology [21]. This paper further develops the patent citation system by using text mining technology, retrieves and downloads the title text of the focal patent, its cited literature and the cited patents, constructs a scientific knowledge network based on the co-occurrence of keywords in the cited literature and a technological knowledge network based on the co-occurrence of keywords in the cited patents, deconstructing the stage innovation characteristics of synthetic biotechnology evolution from the perspective of network evolution.

\subsection{Data Sources and Retrieval Strategies}

The data in this paper comes from the Web of Science (WOS). WOS is an academic index platform with great influence worldwide. It includes the Science Citation Index (SCIE), the Social Science Citation Index (SSCI) and other literature index databases, as well as the Derwent World Patent Index (DII). Compared with the USPTO and the EPO, DII covers patent information from many countries and has more comprehensive data, which has advantageous for examining the overall development of emerging technologies. More importantly, WOS provides CrossSearch functions. It is possible to capture the flow of scientific and technological knowledge at the same time by building cross-reference between DII patent database and SCI, SSCI citation index database with unique citation retrieval mechanism and powerful cross-retrieval function.

Keywords are one of the important tools for searching patents and literature. However, the identification of keyword search strategies requires the participation of experts in various fields of the industry. The scientificalness and timeliness determine the rationality of the research samples. This paper refers to the search strategy of synthetic biology keywords proposed by Shapira, Kwon and Youtie, downloads 1385 synthetic biotechnology patents from 2000 to 2014 as focal patents from WOS, and further downloads 43804 cited literature and 36943 cited patents of these focal patents [4]. According to Cameron, Basher and Collins's comments in Nature, the evolution of synthetic biotechnology can be divided into the following three stages: 1) The emergence of two key technologies in 2000-2003 marks the beginning of synthetic biotechnology; 2) Subversive innovation coexisted with major obstacles in 2004-2007, and synthetic biotechnology entered a short exploration stage; 3) From 2008 till now, the first-mover countries such as Britain and the United States began to reorganize the strategic layout of the biotechnology innovation network and enter the growth stage of rapid development [1]. Referring to this division, this paper divides the total sample into sub-samples for network characteristics analysis: emergence stage, exploration stage, and growth stage (Table 1). The data was downloaded in December, 2017.

\subsection{Network Characteristic Index System}

Empirical analysis based on network characteristic index system includes two 
Table 1. Descriptive statistics of patents in different evolution stages.

\begin{tabular}{cccc}
\hline $\begin{array}{c}\text { Evolution Stage of Synthetic } \\
\text { Bio-technology }\end{array}$ & Focal patents & Cited literature & Cited patents \\
\hline Emergence stage (2000-2003) & 456 & 20,467 & 15,891 \\
Exploration stage (2004-2007) & 336 & 9077 & 9706 \\
Growth stage (2008-2014) & 593 & 14,260 & 11,346 \\
Total & 1385 & 43,804 & 36,943 \\
\hline
\end{tabular}

parts: 1) Analyze the structural characteristics of multiple knowledge networks by using network structure indicators, including network density, network degree distribution, connectivity of the networks, the pattern of clustering; 2) Analyze the characteristics of multiple knowledge network nodes by using Term Frequency-Inverse Document Frequency (TF-IDF), which is a network node index.

\subsection{Multiple Knowledge Networks}

After multiple screening and cleaning of the sample data, we use the visual text analysis tool CiteSpace to generate the keyword co-occurrence map, and then extract the literature and patent title keyword data, and use the complex network analysis integration software Ucinet to draw a clearer large-scale keyword co-occurrence network, thus obtaining the keyword co-occurrence network of focal patents, cited literature and cited patents at different research stages. In the overall network structure, the larger the node, the more the keyword appears in the title of the literature or patents' report, and the higher the co-occurrence frequency with other keywords. It is not difficult to find that there are many component networks (a group of related knowledge clusters) in the focal patents and cited literature and post-introduction patent keywords in each period. What's more, there are reachable paths between keywords in the component networks, but there is no connection between different component networks. It can be seen that secondary aggregation is formed within the network, and the evolution of the overall network can be decomposed into the evolution of each secondary network, which implies that even within the same network, there are still multiple technological subject development paths. At the same time, with the continuous development of synthetic biotechnology, the focal patents keyword network has been deepened, and the cited literature and the cited patent keyword network have presented different network characteristics. Therefore, it is helpful to deconstruct the evolution of synthetic biotechnology to analyze the multiple knowledge network from two dimensions: overall network structure and knowledge element network node characteristics.

\section{Analysis of Structural Characteristics of Multiple Knowledge Network}

\subsection{Emergence Stage}

According to the co-occurrence network of focal patents and its cited literature 
and patents at the emergence stage (Figures 1-3), we found that, firstly, from the perspective of network density, the network density (0.015) of the cited literature is basically the same as the focal patents network density (0.016), which is lower than the cited patents $(0.025)$. It shows that scientific knowledge is loose and technological knowledge is close at the emergence stage, and the distribution of innovation in synthetic biotechnology has high randomness. Secondly, from the perspective of network degree centrality, there are great differences between different knowledge networks. The degree centrality of the focal patent network, the cited literature and the cited patent network are $0.037,0.649$, and 0.175 respectively. This shows that the core node of scientific knowledge is prominent at the exploration stage, the core node of technological knowledge appears but has not yet been completely formed, and the distribution of synthetic biotechnology innovation is highly discrete. Thirdly, from the point of view of network diameter, the network diameter (3.5) of cited literature is slightly larger than that of cited patents (3.1), and both are much larger than that of focal patents (1.2). This trend is determined by the active knowledge flow of synthetic biotechnology. Fourthly, according to the network cohesive subgroups, the cited network (40) is slightly smaller than the cited patent network (49), which is much larger than the focal patent network (3). This shows that although the degree of differentiation between the post-cited literature network and the post-patent network reaches a certain level, the diversity of synthetic biotechnology innovation is extremely limited. This also implies that there is a certain obstacle in the knowledge fusion between scientific knowledge and technological knowledge at the emergence stage. Professor Endy (2005), the founder of the discipline, classified

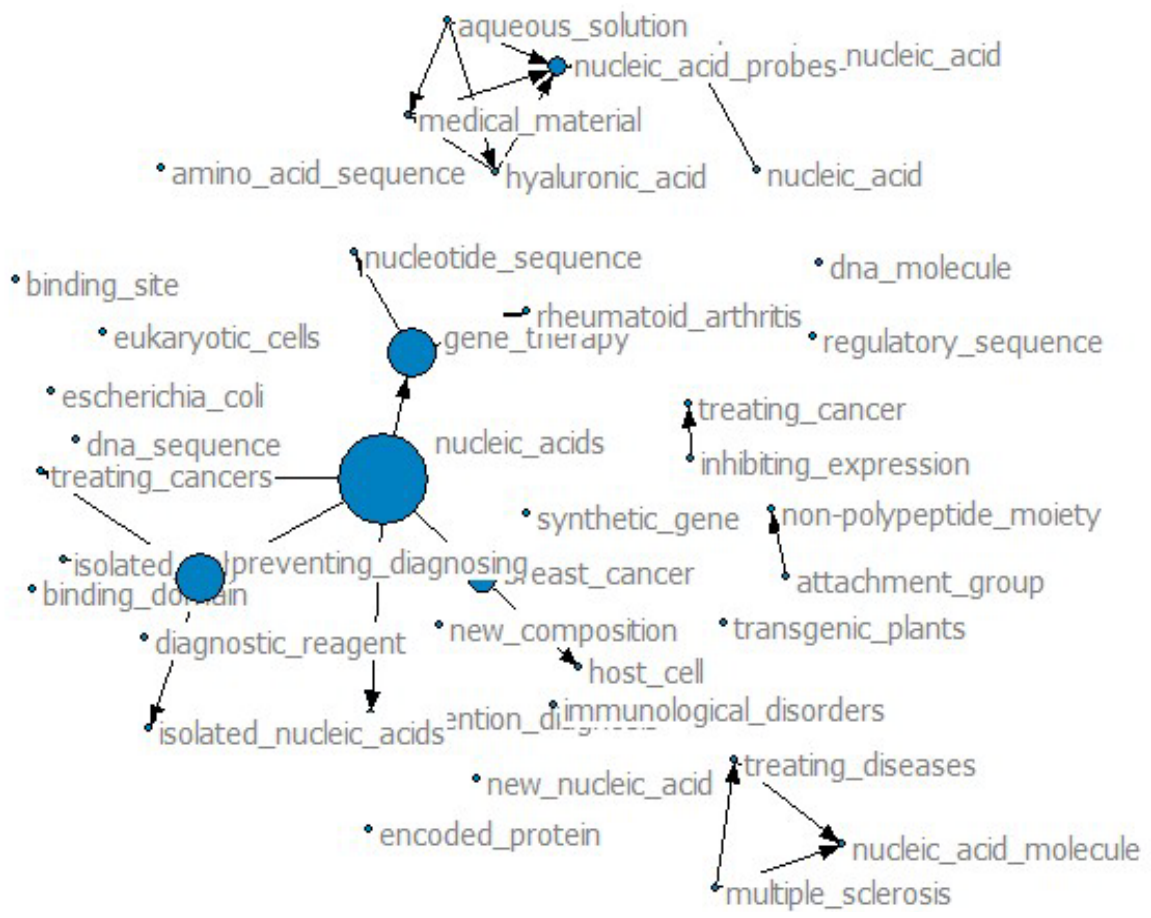

Figure 1. Focal patent co-occurrence network at emergence stage. 


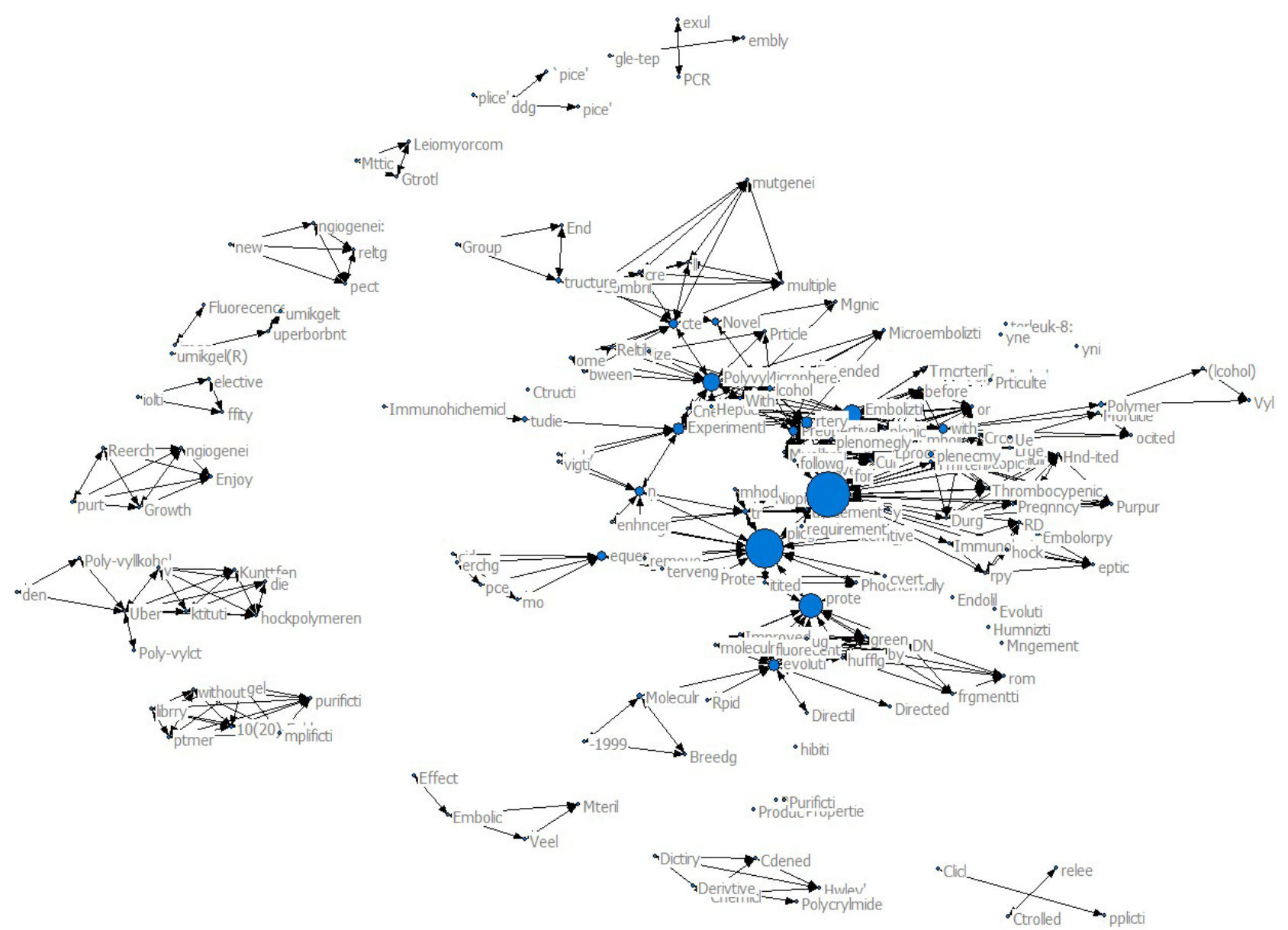

Figure 2. Cited literature co-occurrence network at emergence stage.

it into two major categories: at the scientific level, little is known about biological systems; at the technological level, the engineering level at that time was not sufficient to control the complex microscopic biological system. Although the germination of synthetic biology bridges biology and engineering, the development of the two types of disciplines stems from the independent process of institutional, social structure and background shaping [9].

\subsection{Exploration Stage}

According to the co-occurrence network of focal patents and its cited literature and patents at the exploration stage (Figures 4-6), we found that, firstly, from the perspective of network density, the focal patent network density $(0.030)$ is the same as the cited patent network (0.030), which is much larger than the cited literature network (0.004). The network density of scientific knowledge and technological knowledge at the exploration stage maintained the trend of the emergence stage and further deepened. The connection of scientific knowledge becomes scattered and the connection of technological knowledge becomes closed. However, the innovation of synthetic biotechnology was different from the previous stage and shows a higher sustainability. It shows that the synthetic 
- monoclonal_antibody

-immune_response

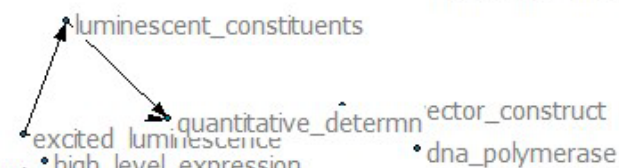

- mammalian_cells • physical_characterhigh_level_expression

'human_immunodeficiency_virus

- target_sequence

- clinical_diag_-alid_support

- tranenonic animals

- solid_substrate

Ynew_recombinant_dnalating expression

- Ina coquences new_nucleic_acid

iamino_acid_sequence

$\int_{\text {othertarget_genet }}$

• hiv_infection • nucleotide_probes_-polynucleotides



• hiv_infection • nucleotide_probes__polynucleotides

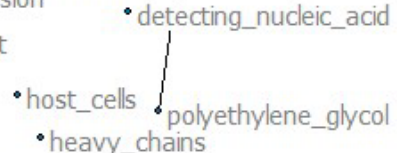

\%odulating gene expression adenovirus.s disease

-polymerase_chain_reactions
•disposable_container

- new_dna

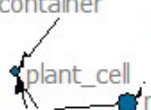

7 nucleic_acids-expression

-cell_proliferation

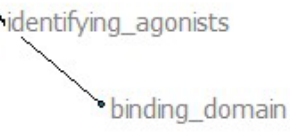

*unknown hase-C- nucleic_acid_sequence

- microfluidic_device nucleic_acid

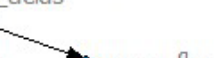

Coscent protein

diseases

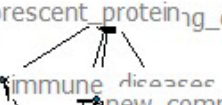

- metabolic disorders

- gene_functiomicrofluidic_system-compound

- modifying_agent ${ }^{3 p y}$ _vectors

\$immune dicascoc

Comprising_immunoglobulins

Figure 3. Cited patent co-occurrence network at emergence stage.

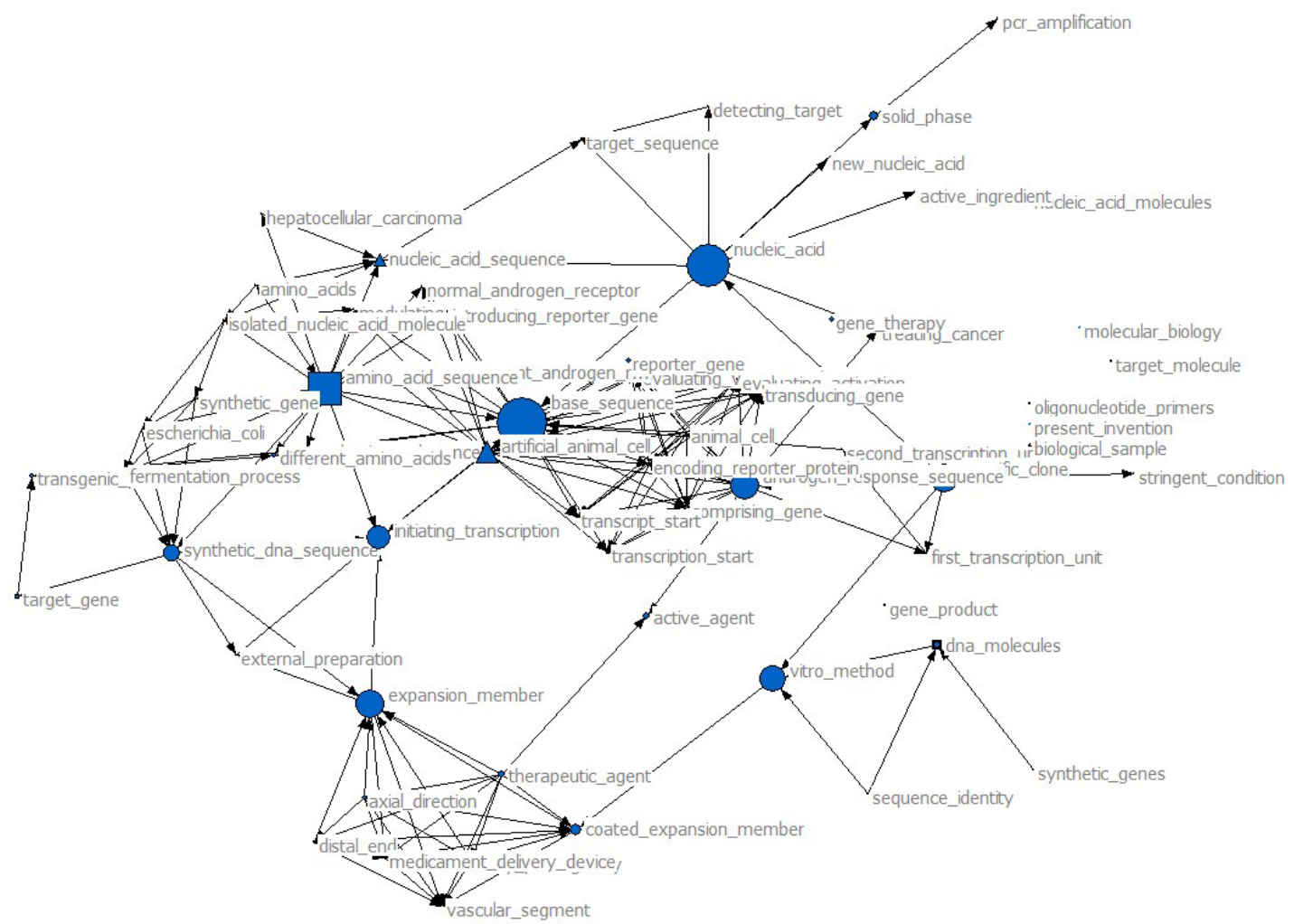

Figure 4. Focal patent co-occurrence network at exploration stage. 


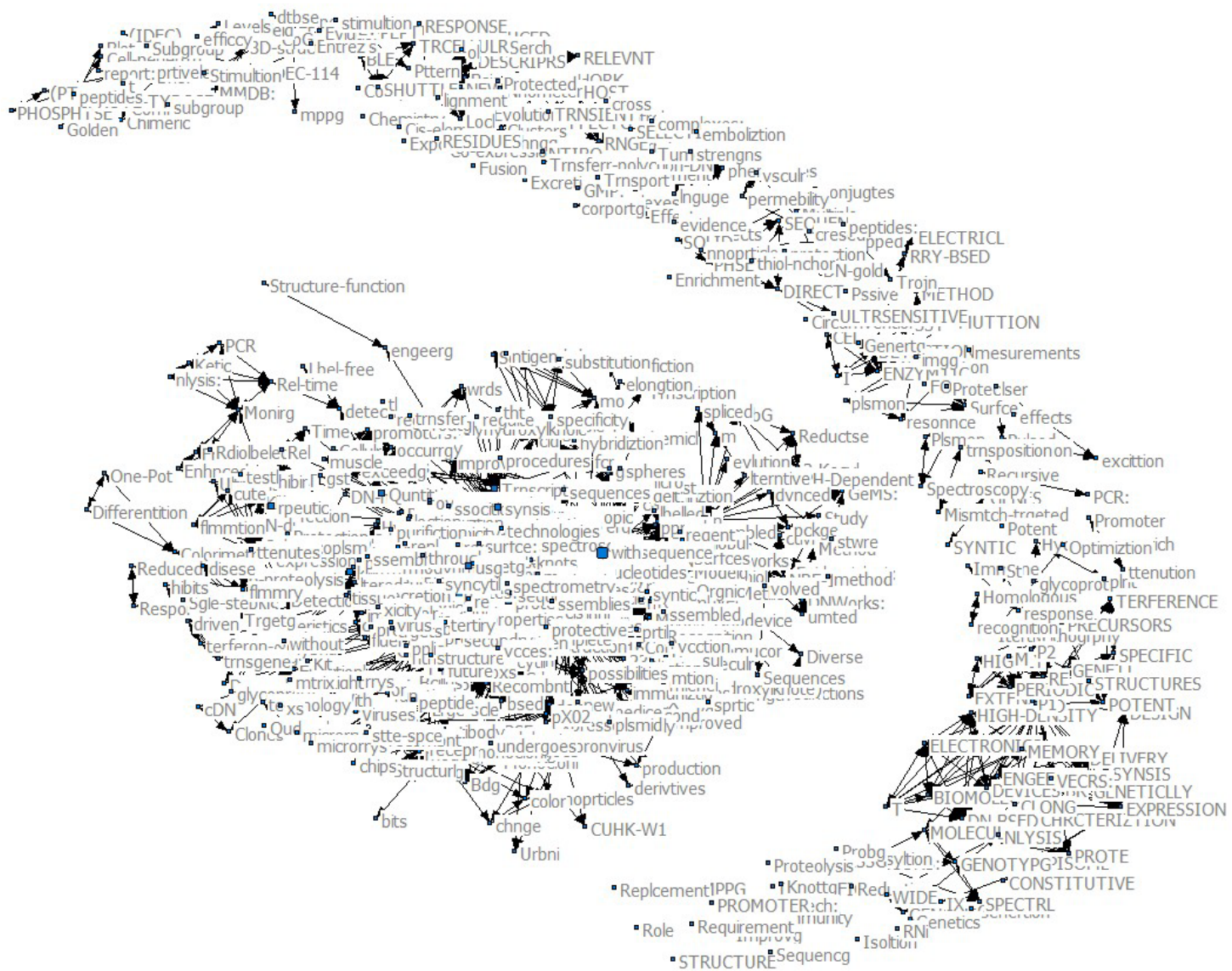

Figure 5. Cited literature co-occurrence network at exploration stage.

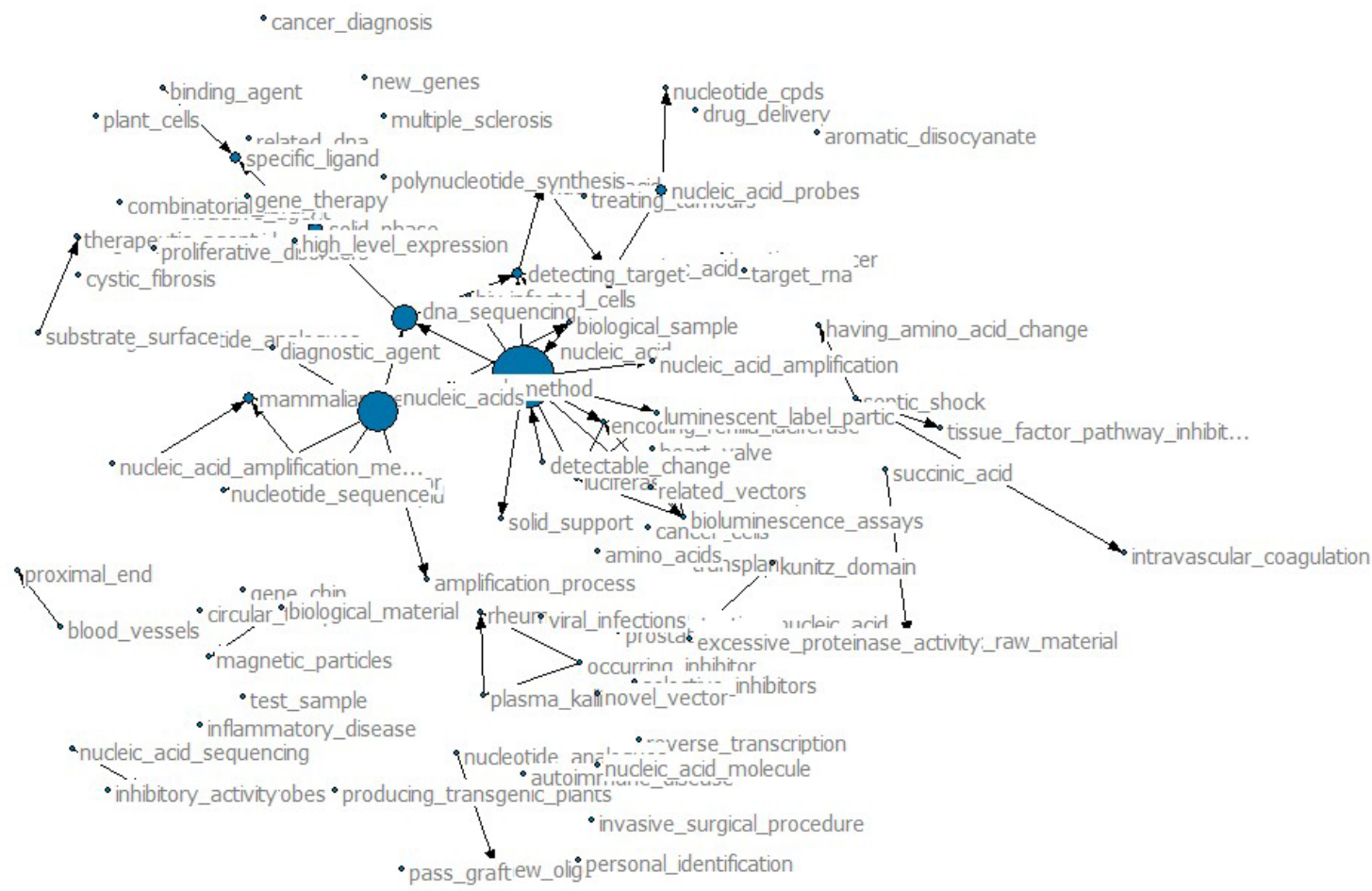

Figure 6. Cited patent co-occurrence network at exploration stage. 
biotechnology innovation has changed during the exploration period. Secondly, from the perspective of network degree centrality, the degree centrality of the cited literature $(0.665)$ and the cited patents $(0.175)$ both maintain the aggregation degree of the aggregation of knowledge nodes from the absolute number or the relative number, but the degree centrality of the focal patents $(0.149)$ has been greatly improved. This shows that the innovation of synthetic biotechnology was no longer too discrete, the core areas were gradually determined during the exploration stage. Thirdly, from the point of view of network diameter, the network diameter of the focal patent, the cited literature, and the cited patent are $1.4,3.2$, and 3.8 respectively, fluctuating but basically consistent with the previous stage. Fourthly, according to the network cohesive subgroup, compared with the previous stage, the differentiation degree of the focal patent network (20), the cited literature network (194) and the cited patent network (76) is greatly improved. Explain that the scientific knowledge and technical knowledge have merged during the exploration period and jointly promoted the innovation of synthetic biotechnology. Life science and engineering began to merge rapidly. Technological advances such as gene synthesis, deletion and editing have made it possible to connect theoretical research and applied research of synthetic biotechnology. The top-down research method based on the redesign of existing gene sequences intersects with the bottom-up research method based on non-living components to construct life systems. More and more scientific research teams attached importance to the two-way extension of synthetic biology to engineering and molecular biology, not only the molecular components required for complex gene circuits, but also the technical methods for adapting gene circuits.

\subsection{Growth Stage}

According to the co-occurrence network of focal patents and its cited literature and patents at the growth stage (Figures 7-9), we found that, firstly, from the perspective of network density, the density of knowledge networks at all levels showed a significant decline. The focal patent network and the cited literature network were highly dispersed: the focal patent network density was 0.002 , the cited literature network density was 0.002 , and the cited patent network density was 0.015 . Further comparing the total number of nodes and the number of connected edges of nodes in the network density index, it is found that the scale of each layer of knowledge network has an exponential transition. Secondly, from the perspective of network degree centrality, compared with the previous stage, the focal patent network degree centrality, (0.125) decreased slightly but remained basically the same, while the cited document network (0.375) and the cited patent network (0.072) decreased significantly. It can be seen that the scientific knowledge and technical knowledge elements at the growth stage were gradually enriched, and the research fields and topics were scattered. However, it has not caused great changes in the level of innovation. Thirdly, from the point 


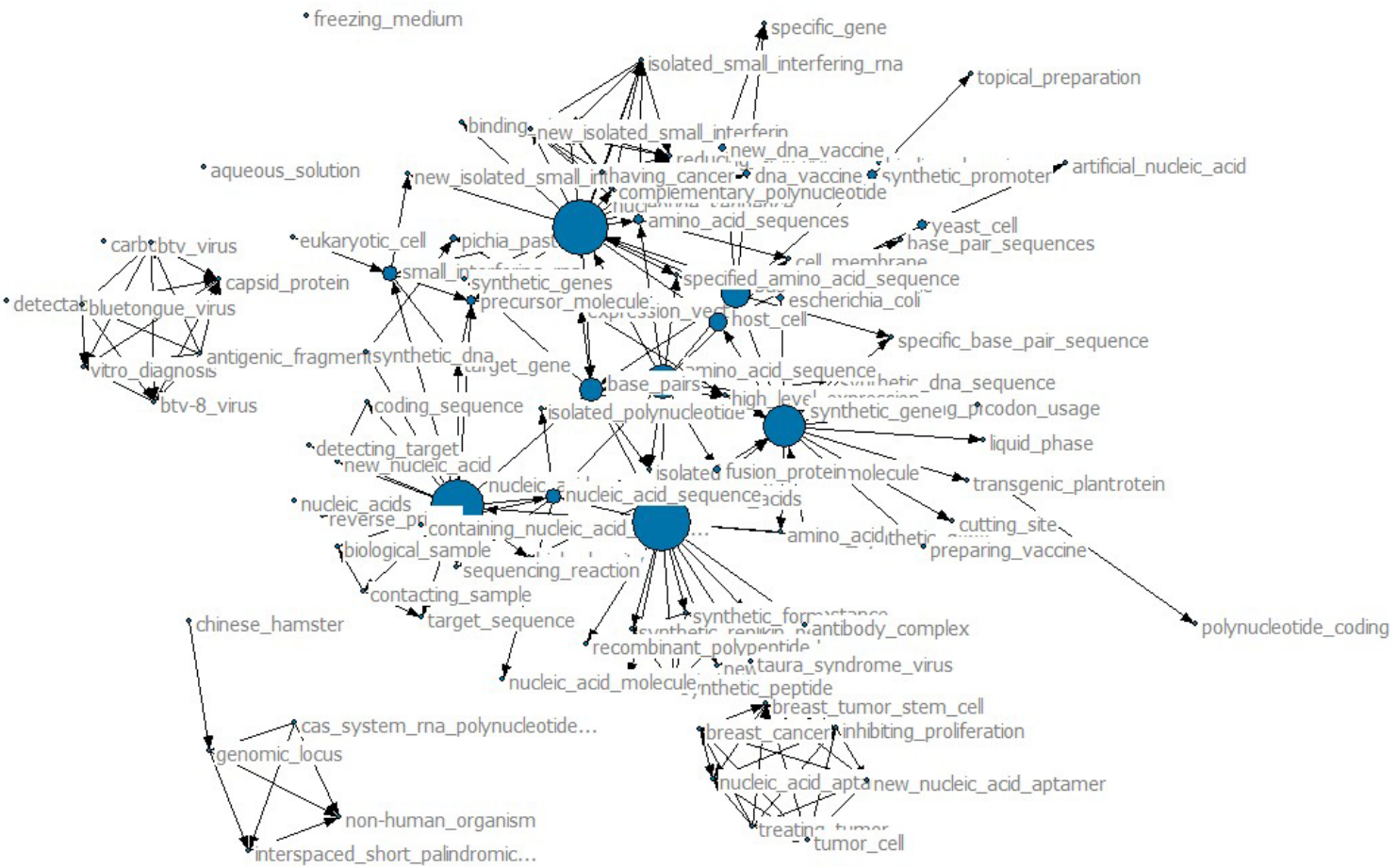

Figure 7. Focal patent co-occurrence network at growth stage.

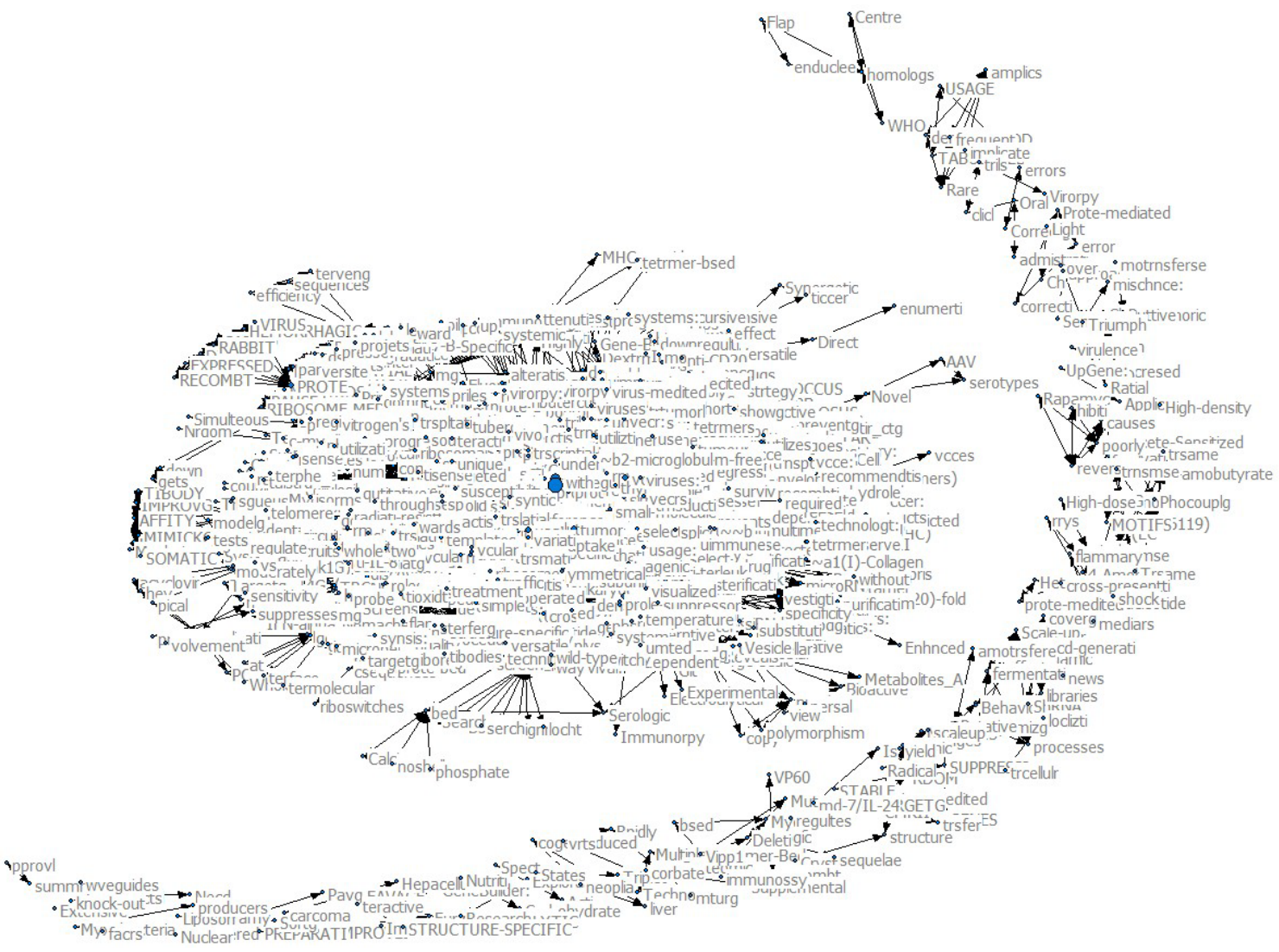

Figure 8. Cited literature co-occurrence network at growth stage. 




Figure 9. Cited patent co-occurrence network at growth stage.

of view of network diameter, the diameter of the cited literature network (2.9) and the cited patent network (3.3) have not changed substantially compared with the exploration stage, but the diameter of the focal patent network has increased greatly, reaching 4.1. Fourthly, according to the network cohesive subgroup, the network cohesive subgroup of the focal patent, the cited literature, and the cited patent are 34, 611, and 117 respectively, all of which are greatly improved, especially the scientific knowledge shows a trend of highly differentiation. After a short period of co-evolution, major common scientific and technological problems hindering industrial innovation have been effectively solved. Science and technology have reached such a level that they can break through the structural dilemma of mutual restriction and basically realize the standardized, decoupled and modularized innovation mode [21]. Since the year of 2008, the United States, Britain, the European Union and other countries and regions have begun to adjust their strategic layout and reorganize the global synthetic biotechnology map, consciously placing science and technology on a relatively separate development track to meet the relatively independent growth logic, so as to maximize innovation output. Taking the United States as an example, judging from the scale of government funding, the amount of U.S. government 
funding for synthetic biology research was less than 2 million U.S. dollars before 2008, and reached 200 million U.S. dollars by 2014. From the perspective of government-funded institutions, the relevant funding in 2008 was basically provided by the National Institutes of Health. In 2014, public funding sources included the US Defense Advanced Research Projects Agency, the Ministry of National Defense, the National Science Foundation, the Department of Energy, and the Department of Health and Human Services, Ministry of Agriculture, etc. From the perspective of government funding model, the US Department of Defense has formed a clear classification of funding in the field of synthetic biology, from a single category of funding for army research in 2014 to a parallel category of funding for navy, army, chemistry, biological select agents and toxins and national defense secrets in 2018.

\section{Analysis of Network Node Characteristics of Multiple Knowledge Network}

\subsection{Emergence Stage}

At the emergence stage of synthetic biotechnology, the comparison of TF-IDF values of multiple knowledge network keywords shows (Table 2): 1) In the focal patents keyword co-occurrence network, the top five keywords of TF-IDF value are nucleic acid, amino acid, amino acid sequence, TF technology focus and gene therapy. 2) In the co-occurrence network of cited patents keywords, the high TF-IDF values are nucleic acid, gene therapy, amino acid and amino acid sequence, etc. Compared with the co-occurrence network of focal patent keywords, the core research fields and themes of the two networks are basically the same. 3) In the network of cited literature, the TF-IDF values ranked higher in gene expression, binding protein, monoclonal antibody, amino acid and binding domain, etc. Compared with the focal patents keyword co-occurrence network, the core research field of the cited literature/patents is mainly focused on protein engineering and genetic engineering, but the core research themes are quite

Table 2. TF*IDF of multilevel knowledge networks at the emergence stage.

\begin{tabular}{|c|c|c|c|c|c|}
\hline Focal Patent & $\mathrm{TF}^{\star} \mathrm{IDF}$ & Cited Patent & $\mathrm{TF}^{\star} \mathrm{IDF}$ & Cited Literature & $\mathrm{TF}^{\star} \mathrm{IDF}$ \\
\hline Nucleic acid & 108.13 & Nucleic acid & 148.07 & Gene expression & 87.63 \\
\hline Amino acids & 96.71 & Gene therapy & 138.43 & Binding protein & 64.27 \\
\hline $\begin{array}{l}\text { Amino acid } \\
\text { sequence }\end{array}$ & 82 & Nucleic acids & 121.3 & $\begin{array}{l}\text { Monoclonal } \\
\text { antibody }\end{array}$ & 62.19 \\
\hline $\begin{array}{l}\text { TF technology } \\
\text { focus }\end{array}$ & 72.09 & Host cell & 54.77 & Amino acid & 82.92 \\
\hline Gene therapy & 56.44 & $\begin{array}{l}\text { Nucleic acid } \\
\text { sequence }\end{array}$ & 54.77 & Binding domain & 48.43 \\
\hline$\cdots$ & $\ldots$ & $\cdots$ & $\ldots$ & $\cdots$ & $\ldots$ \\
\hline $\begin{array}{c}\text { Acetyl } \\
\text { coenzyme }\end{array}$ & 14.87 & $\begin{array}{l}\text { Antimicrobial } \\
\text { agent }\end{array}$ & 17.85 & $\begin{array}{c}\text { Bacillus } \\
\text { thuringiensis }\end{array}$ & 12.78 \\
\hline
\end{tabular}


different. In particular, the nucleic acid ranked first in TF-IDF value in the basic patent keyword co-occurrence network is ranked lower in the post-citation keyword co-occurrence network, which shows that it is not the focus of synthetic biotechnology research in the emergence stage. From the core research field and core research themes, the similarity between the cited literature and the focal patents is low in the emergence stage of synthetic biotechnology, but the similarity between the cited patents and the focal patents is high, innovation mainly depends on technical knowledge.

\subsection{Exploration Stage}

At the exploration stage of synthetic biotechnology, the comparison of TF-IDF values of multiple knowledge network keywords shows (Table 3): 1) In the co-occurrence network of focal patents keywords, the high TF-IDF values are nucleic acid, amino acids, amino acid sequence, synthetic gene, nucleotide sequence and DNA sequence, etc. 2) In the co-occurrence network of cited patents keywords, the high TF-IDF values are nucleic acid, new nucleic acid, nucleic acid sequences, rheumatoid arthritis and DNA sequencing, etc. Compared with the focal patents keyword co-occurrence network, although some research themes have differences, the core research field and themes are basically the same. 3) In the co-occurrence network of cited literature keywords, the high TF-IDF values are amino acids, nucleic acid, fusion protein, nucleic acids and gene product, etc. Compared with the co-occurrence network of focal patent keywords, the core research fields and themes of the two networks are basically the same. It can be found that the core research field and the core research theme of the keyword co-occurrence networks of focal patents and those focal patents' cited literature/patents are basically the same, and the research field and research theme are also basically the same among the interval multiple knowledge networks with

Table 3. TF*IDF of multilevel knowledge networks at the exploration stage.

\begin{tabular}{|c|c|c|c|c|c|}
\hline Focal Patent & $\mathrm{TF}^{\star} \mathrm{IDF}$ & Cited Patent & $\mathrm{TF}^{\star} \mathrm{IDF}$ & $\begin{array}{c}\text { Cited } \\
\text { Literature }\end{array}$ & $\mathrm{TF}^{\star} \mathrm{IDF}$ \\
\hline Nucleic acid & 57.15 & Nucleic acid & 203.98 & Amino acids & 60.68 \\
\hline Amino acids & 52.78 & $\begin{array}{c}\text { New nucleic } \\
\text { acid }\end{array}$ & 78.42 & Nucleic acid & 19.32 \\
\hline $\begin{array}{l}\text { Amino acid } \\
\text { sequence }\end{array}$ & 48.16 & $\begin{array}{l}\text { Nucleic acid } \\
\text { sequences }\end{array}$ & 64.47 & Fusion protein & 13.39 \\
\hline $\begin{array}{l}\text { Nucleotide } \\
\text { sequence }\end{array}$ & 36.25 & $\begin{array}{c}\text { Rheumatoid } \\
\text { arthritis }\end{array}$ & 60.87 & Nucleic acids & 13.43 \\
\hline $\begin{array}{l}\text { Synthetic } \\
\text { gene }\end{array}$ & 36.25 & $\begin{array}{c}\text { DNA } \\
\text { sequencing }\end{array}$ & 60.87 & Gene product & 8.40 \\
\hline$\cdots$ & $\cdots$ & $\cdots$ & $\cdots$ & $\cdots$ & $\cdots$ \\
\hline $\begin{array}{l}\text { Androgen } \\
\text { response } \\
\text { sequence }\end{array}$ & 13.79 & $\begin{array}{c}\text { Therapeutic } \\
\text { agent }\end{array}$ & 17.05 & $\begin{array}{l}\text { Nucleotide } \\
\text { sequences }\end{array}$ & 4.73 \\
\hline
\end{tabular}


intermediate TF-IDF value. From the core research field and core research themes, compared with the g emergence stage, a significant feature is that the research field and the core research of the cited literature and the focal patent keyword co-occurrence network have high consistency. It indicates that the similarity among the focal patents and those focal patents' cited literature/patents at the exploration stage of synthetic biotechnology is high, and innovation depends on new scientific and technological knowledge at the same time.

\subsection{Growth Stage}

At the growth stage of synthetic biotechnology, the comparison of TF-IDF values of multiple knowledge network keywords shows (Table 4): 1) In the co-occurrence network of focal patents keywords, the high TF-IDF values are nucleic acid, nucleotide sequence, synthetic gene, amino acids, amino acid sequence and host cell, etc. 2) In the co-occurrence network of cited patents keywords, the high TF-IDF values are nucleic acids, nucleic acid sequence, treating cancer, gene therapy, host cell and acetic acid, etc. Compared with the focal patents keyword co-occurrence network, although some research themes have differences, the core research field and themes are basically the same. 3) In the co-occurrence network of cited literature keywords, the high TF-IDF values are gene expression, nucleic acid, amino acids, breast cancer, tumor cell and plant genes, etc. Compared with the focal patents keyword co-occurrence network, although some research themes have differences, the core research field and themes are basically the same. It can be found that when the cited literature/patents keyword co-occurrence network and the focal patent keyword co-occurrence network are compared respectively, the core research field and themes are basically the same. However, when we compare the keyword co-occurrence network of the cited literature with the keyword co-occurrence network of the cited patents, we found that the core research themes are quite

Table 4. TF*IDF of multilevel knowledge networks at the growth stage.

\begin{tabular}{|c|c|c|c|c|c|}
\hline Focal Patent & $\mathrm{TF}^{\star} \mathrm{IDF}$ & Cited Patent & $\mathrm{TF}^{\star} \mathrm{IDF}$ & $\begin{array}{c}\text { Cited } \\
\text { Literature }\end{array}$ & $\mathrm{TF}^{\star} \mathrm{IDF}$ \\
\hline Nucleic acid & 117.43 & Nucleic acids & 183.49 & $\begin{array}{c}\text { Gene } \\
\text { expression }\end{array}$ & 133.68 \\
\hline $\begin{array}{l}\text { Nucleotide } \\
\text { sequence }\end{array}$ & 88.72 & $\begin{array}{l}\text { Nucleic acid } \\
\text { sequence }\end{array}$ & 125.68 & Nucleic acid & 78.93 \\
\hline $\begin{array}{l}\text { Synthetic } \\
\text { gene }\end{array}$ & 85 & $\begin{array}{l}\text { Treating } \\
\text { cancer }\end{array}$ & 118.67 & Amino acids & 53.65 \\
\hline Amino acids & 79.5 & Gene therapy & 111.47 & Breast cancer & 46.60 \\
\hline $\begin{array}{l}\text { Amino acid } \\
\text { sequence }\end{array}$ & 62.62 & Host cell & 104 & Tumor cell & 28.94 \\
\hline$\cdots$ & $\cdots$ & $\cdots$ & $\cdots$ & $\cdots$ & $\cdots$ \\
\hline $\begin{array}{c}\text { Artificial cell } \\
\text { membrane }\end{array}$ & 15.49 & Acetic acid & 20.18 & Plant genes & 10.47 \\
\hline
\end{tabular}


different. From the point of view of the core research field and themes, compared with the exploration period, the similarity between the later cited literature or the cited patents and the basic patents has been improved, but the similarity between the cited literature and the cited patents shows a decreasing trend. Synthetic biotechnology innovation relies on relatively independent scientific and technological knowledge pathways.

\section{Conclusions and Future Directions}

From the perspective of global evolution, after more than ten years of development, synthetic biotechnology has completed the symbiosis of resources at the emergence stage and the exploration stage, and entered a new strategic pattern of radiation to the world centered on the UK and the United States. In order to provide theoretical basis for formulating scientific and technological policies and planning industrial layout, this paper proposes an analysis framework integrating scientific knowledge network and techno-logical knowledge network to deconstruct the heterogeneous role of science and technology in the evolution of synthetic biotechnology. At the same time, this paper also has the following shortcomings: this paper uses coded patents and literature to explain the relationship between science and technology. Although it captures the dominant knowledge flow to a large extent, it ignores the interactive relationship between science and technology as tacit knowledge, for example, the interaction through industry-university-research cooperation, technology licensing, business consulting and cross-border cooperation. The main conclusions of this paper are as follows.

First, scientific knowledge and technological knowledge are difficult to integrate at the emergence stage of synthetic biotechnology. There are obvious intersections and symbiosis at the exploration stage. What's more, scientific knowledge and technological knowledge differentiate into independent growth logic in the growth period. The analysis of structural characteristics of multiple knowledge networks in the evolution of synthetic biotechnology indicates: 1) At the emergence stage (2000-2003), scientific knowledge is relatively loose, core nodes are prominent. But technical knowledge is relatively close, and there is a certain tendency to focus on core nodes. There are certain obstacles in the integration of knowledge, it is manifested that there is little knowledge of biological systems at the scientific level, and the technical level is not enough to control complex microscopic biological systems. Synthetic biotechnology innovations have high randomness and dispersion. 2) At the exploration stage (2004-2007), technological advances such as gene synthesis, deletion and editing made it possible to connect theoretical research and applied research of synthetic biotechnology. The connection of scientific knowledge is looser and the connection of technical knowledge is closer, but the innovation of synthetic biotechnology is different from the situation of the previous stage, which is too discrete, showing a high degree of continuity. It can be indicated that scientific knowledge and 
technical knowledge have some form of convergence during the exploration period, and jointly promote the innovation of synthetic bio-technology. 3) At the growth stage (2008-2014), the elements of scientific knowledge and technical knowledge are gradually enriched. In addition, the research fields and themes are scattered, major scientific and technological problems that hindering industrial innovation have been effectively solved, and relatively independent growth logic has been differentiated to promote the exponential transition of network scale.

Second, the emergence stage of synthetic biotechnology evolution mainly depends on technological knowledge. The exploration stage mainly relies on scientific knowledge and technical knowledge with high similarity. The growth stage mainly relies on scientific knowledge and technical knowledge with low similarity. The analysis of the characteristics of multiple knowledge network nodes in the evolution of synthetic biotechnology indicates that: 1) At the emergence stage (2000-2003), the similarity between scientific knowledge and innovation network is low, while the similarity between technological knowledge and innovation network is high. Synthetic biotechnology innovation mainly depends on technical knowledge. 2) At the exploration stage (2004-2007), the similarity among scientific knowledge, technological knowledge and innovation network is at a high level, suggesting that synthetic biotechnology innovation relies on both scientific and technological new knowledge. 3) At the growth stage (2008-2014), Both scientific knowledge and technical knowledge have high similarities with innovation networks, but the similarity between the two types of knowledge networks is low, indicating that synthetic biotechnology innovation relies on relatively independent scientific and technological knowledge paths.

We believe that future research can be further extended from a synthetic biotechnology scenario to a more general emerging technology scenario. In recent years, emerging technologies such as artificial intelligence and digital manufacturing often span the two categories of science and technology, involving multiple research fields. Moreover, disruptive innovation triggered by these emerging technologies is closely related to the interaction between science and technology. So, the research on the evolution of multiple knowledge networks based on the technology life cycle has research prospects and research values. In addition, stage evolution research can be extended to dynamic evolution research. Relevant studies published in top international journals of management science in recent years have proved the dynamic nature of network indicators and the heterogeneity between cooperative networks and knowledge networks. However, insufficient attention has been paid to the dynamic evolution of "core relationships" between multiple networks, especially multiple knowledge networks. The relevant conclusions are likely to provide some important innovation management inspiration for the complex network field.

\section{Conflicts of Interest}

The authors declare no conflicts of interest regarding the publication of this paper. 


\section{References}

[1] Cameron, D.E., Bashor, C.J. and Collins, J.J. (2014) A Brief History of Synthetic Biology. Nature Reviews Microbiology, 12, 381-390.

https://doi.org/10.1038/nrmicro3239

[2] Si, T. and Zhao, H. (2016) A Brief Overview of Synthetic Biology Research Programs and Roadmap Studies in the United States. Synthetic \& Systems Biotechnology, 1, 258-264. https://doi.org/10.1016/j.synbio.2016.08.003

[3] Clarke, L.J. and Kitney, R.I. (2016) Synthetic Biology in the UK-An Outline of Plans and Progress. Synthetic \& Systems Biotechnology, 1, 243-257.

https://doi.org/10.1016/j.synbio.2016.09.003

[4] Shapira, P., Kwon, S. and Youtie, J. (2017) Tracking the Emergence of Synthetic Biology. Scientometrics, 112, 1439-1469. https://doi.org/10.1007/s11192-017-2452-5

[5] Endy, D. (2005) Foundations for Engineering Biology. Nature, 438, 449-453. https://doi.org/10.1038/nature04342

[6] Phelps, C., Heidl, R. and Wadhwa, A. (2012) Knowledge, Networks, and Knowledge Networks: A Review and Research Agenda. Journal of Management, 38, 1115-1166. https://doi.org/10.1177/0149206311432640

[7] Brennecke, J. and Rank, O.N. (2017) The Firm's Knowledge Network and the Transfer of Advice among Corporate Inventors. Research Policy, 46, 768-783. https://doi.org/10.1016/j.respol.2017.02.002

[8] Guan, J. and Liu, N. (2015) Exploitative and Exploratory Innovations in Knowledge Network and Collaboration Network: A Patent Analysis in the Technological Field of Nano-Energy. Research Policy, 45, 97-112. https://doi.org/10.1016/j.respol.2015.08.002

[9] Bensaude-Vincent, B. (2013) Discipline Building in Synthetic Biology. Studies in History and Philosophy of Science Part C: Studies in History and Philosophy of Biological and Biomedical Sciences, 44, 122-129. https://doi.org/10.1016/j.shpsc.2013.03.007

[10] Ahuja, G., Soda, G. and Zaheer, A. (2012) The Genesis and Dynamics of Organizational Networks. Organization Science, 23, 434-448. https://doi.org/10.1287/orsc.1110.0695

[11] Cannella, A.A. and McFadyen, M.A. (2016) Changing the Exchange: The Dynamics of Knowledge Worker Ego Networks. Journal of Management, 42, 1005-1029. https://doi.org/10.1177/0149206313511114

[12] Demirkan, I., Deeds, D.L. and Demirkan, S. (2013) Exploring the Role of Network Characteristics, Knowledge Quality, and Inertia on the Evolution of Scientific Networks. Journal of Management, 39, 1462-1489. https://doi.org/10.1177/0149206312453739

[13] Guan, J., Zhang, J. and Yan, Y. (2015) The Impact of Multilevel Networks on Innovation. Research Policy, 44, 545-559. https://doi.org/10.1016/j.respol.2014.12.007

[14] Schiffauerova, A. and Beaudry, C. (2012) Collaboration Spaces in Canadian Biotechnology: A Search for Gatekeepers. Journal of Engineering \& Technology Management, 29, 281-306. https://doi.org/10.1016/j.jengtecman.2012.03.004

[15] Yayavaram, S. and Ahuja, G. (2008) Decomposability in Knowledge Structures and Its Impact on the Usefulness of Inventions and Knowledge-Base Malleability. Administrative Science Quarterly, 53, 333-362. https://doi.org/10.2189/asqu.53.2.333

[16] Yan, Y. and Guan, J. (2018) How Multiple Networks Help in Creating Knowledge: 
Evidence from Alternative Energy Patents. Scientometrics, No. 4, 1-27. https://doi.org/10.1007/s11192-018-2638-5

[17] Chen, Z. and Guan, J. (2015) The Core-Peripheral Structure of International Knowledge Flows: Evidence from Patent Citation Data. $R \& D$ Management, 46, 62-79. https://doi.org/10.1111/radm.12119

[18] Guan, J., Yan, Y. and Zhang, J.J. (2017) The Impact of Collaboration and Knowledge Networks on Citations. Journal of Informetrics, 11, 407-422. https://doi.org/10.1016/j.joi.2017.02.007

[19] Fan, X., Liu, W. and Zhu, G. (2017) Scientific Linkage and Technological Innovation Capabilities: International Comparisons of Patenting in the Solar Energy Industry. Scientometrics, 111, 117-138. https://doi.org/10.1007/s11192-017-2274-5

[20] Wu, C.Y. and Mathews, J.A. (2012) Knowledge Flows in the Solar Photovoltaic Industry: Insights from Patenting by Taiwan, Korea and China. Research Policy, 41, 524-540. https://doi.org/10.1016/j.respol.2011.10.007

[21] No, H.J., An, Y. and Park, Y. (2015) A Structured Approach to Explore Knowledge Flows through Technology-Based Business Methods by Integrating Patent Citation Analysis and Text Mining. Technological Forecasting \& Social Change, 97, 181-192. https://doi.org/10.1016/j.techfore.2014.04.007 